\title{
TENSILE DEFORMATION CHARACTERISTICS OF TI-6AL-4V (ELI GRADE) AND EFFECT OF INTERSTITIAL CONTENT
}

\author{
N. Ranganayakulu \\ Lecturer in Mechanical Engineering, M.B.T.S.Govt. Polytechnic, Guntur, India \\ Dr. A.V.S.S.K.S. Gupta \\ Professor in Mechanical Engineering, JNTUH, Hyderabad, India \\ Dr. N. Eswara Prasad \\ Director, Defence Materials \& Stores R\&D Establishment (DMSRDE), Kanpur, India
}

\begin{abstract}
Anisotropy in tensile deformation of the Ti-6Al-4V (Ti-31) and Ti-6Al-4V extra low interstitials (ELI grade) was investigated and effect of interstitial on tensile deformation was discussed. Also reported in brief the details of chemical composition, microstructure of Ti-6Al-4V (ELI grade).The study reveals the tensile strength is more in circumferential direction than radial direction for Ti-6Al-4V (ELI grade) and due low extra interstitials the strength of alloy decreases.
\end{abstract}

Cite this Article: N. Ranganayakulu, A.V.S.S.K.S. Gupta and N. Eswara Prasad, Tensile Deformation Characteristics of Ti-6Al-4V (ELI Grade) and effect of Interstitial Content. International Journal of Design and Manufacturing Technology 7(1), 2016, pp. 50-59. https://iaeme.com/Home/issue/IJDMT?Volume=7\&Issue=1

\section{INTRODUCTION}

Ti-6Al-4V is the most widely used alloy of all the $\alpha+\beta$ titanium compositions. The aluminum stabilizes and strengthens the alpha phase, so raising the $\beta$ - transus temperature as well as reducing the density of alloy. The vanadium is $\beta$ stabilizer, which leads to a greater amount of the more ductile $\beta$ phase during hot working. It may be heat treated to a range of strength levels and in its fully aged condition, is successfully used in highly stressed welded structures. However, in the maximum strength conditions, careful attention must be given to the fracture toughness in a design of highly stressed parts. Harden ability is limited and fracture toughness is 
poor a low temperatures. Low temperature applications should employ the extra low interstitial (ELI) grades. The alloy exhibits some susceptibility to environment assisted cracking in halide containing aqueous environments and in hydrogen. Improved properties are obtained by using ELI grade. Titanium alloy Ti-6Al-4V (ELI grade) material is selected for its fabrication due to high strength to weight ratio, high corrosion resistance, and good fracture toughness to yield strength ratio and well established welding technology for this material. Ti-6Al-4V ELI grade is similar to Ti-6Al-4V, except that Ti-6Al-4V Eli grade contains reduced levels of oxygen, nitrogen, carbon and Iron. This alloy is stable up to $400^{\circ} \mathrm{C}$ and at the same time having a high damage tolerance ( $\mathrm{K}_{\mathrm{IC}}$ ) especially at cryogenic temperature. $\alpha+\beta$ alloys containing aluminum have substantially greater strength than either $\alpha$ alloys containing $\mathrm{Al}$ or aluminum free $\alpha+\beta$ alloys[2]

\section{CHEMICAL COMPOSITION}

Table 1 Presented the chemical composition of Ti-6Al-4V (ELI grade).

\begin{tabular}{|c|c|c|c|c|c|c|c|c|c|}
\hline $\begin{array}{c}\text { Alloying } \\
\text { Elements }\end{array}$ & $\mathbf{A l}$ & $\mathbf{V}$ & $\mathbf{F e}$ & $\mathbf{O}_{\mathbf{2}}$ & $\mathbf{C}$ & $\mathbf{N}_{\mathbf{2}}$ & $\mathbf{H}_{\mathbf{2}}$ & Others & $\mathbf{T i}$ \\
\hline \% weight & $\mathbf{5 . 5 7}$ & 4.07 & 0.05 & 0.026 & 0.045 & 0.012 & 0.0017 & 0.107 & 90.03 \\
\hline \multicolumn{8}{c|}{ Table1 : Chemical composition of Ti-6Al-4V (ELI grade) } \\
\hline
\end{tabular}

\section{MICROSTRUCTURE}

Microstructure analysis for specimen prepared from forged bar is carried at magnifications $200 \mathrm{X}$ and $500 \mathrm{X} \&$ shall be exhibits that structure resulting from processing within the alpha-beta field.

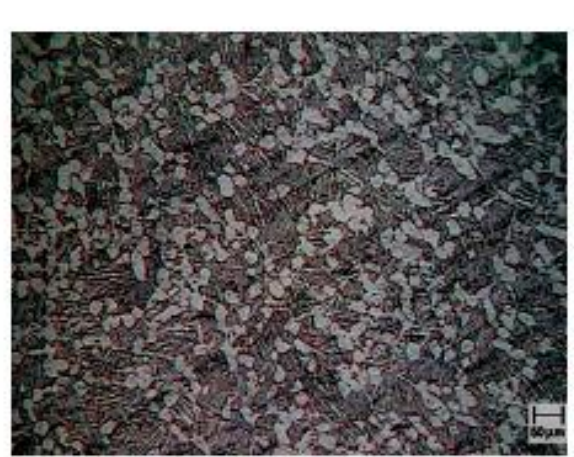

Figure.1 AIR COOLED 200X

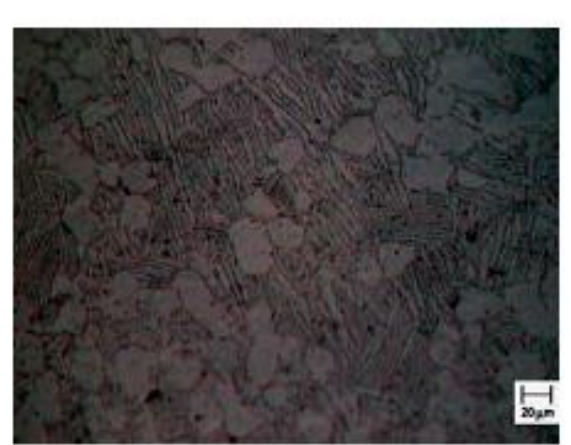

Figure 2 AIR COOLED $500 \mathrm{X}$ 

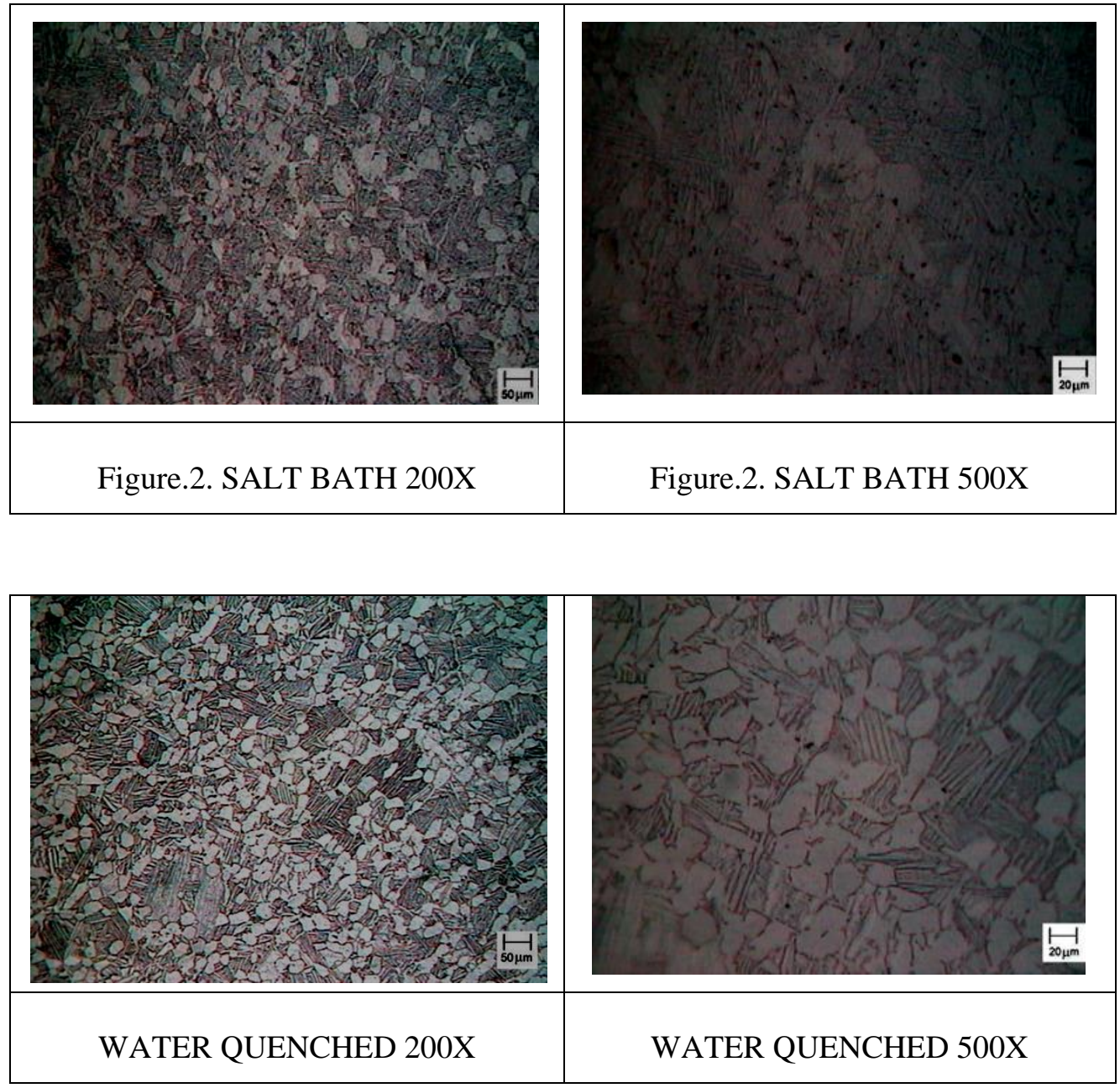

Equi-axed and/or elongated primary alpha in a transformed beta matrix with no continuous network of alpha at prior grain boundaries. The shapes of the primary alpha grains are a mixture of equiaxed and elongated one. Primary alpha grains with high aspect ratio are also observed at some locations. The microstructure results for Ti-6Al-4V are shown in the table.

\begin{tabular}{|c|c|c|c|c|}
\hline $\begin{array}{c}\text { S. } \\
\text { No }\end{array}$ & Quenching media & $\begin{array}{c}\text { Average hardness } \\
\text { value (HV) }\end{array}$ & $\begin{array}{c}\text { ASTM grain } \\
\text { size number }\end{array}$ & $\begin{array}{c}\text { Grain diameter in } \\
\text { microns }\end{array}$ \\
\hline 1 & Water & 261.5 & 7.09 & 31.5 \\
\hline 2 & Brine & 256 & 6.07 & 45 \\
\hline 3 & Oil & 257.3 & 6.1 & 44.5 \\
\hline 4 & Air & 247.7 & 6.46 & 53 \\
\hline
\end{tabular}


Tensile Deformation Characteristics of Ti-6Al-4V (ELI Grade) and effect of Interstitial Content

\subsection{Tensile Deformation Behavior}

Six Nos. of Test tensile specimens ( 2 each for circumferential and radial) are tested for tensile properties of the alloys Ti-6Al-4V (ELI grade) and Ti-6Al-4V to study the anisotropy in tensile deformations and to compare the tensile deformation of Ti-6Al4V (ELI grade) with Ti-6Al-4V. Tensile tests were carried out on Instron 5500-4507200KN.The properties evaluated include the $0.2 \%$ yield stress (YS), the ultimate tensile stress (UTS), \% elongation and uniform strain.

\subsection{Tensile deformation Behavior of Ti-6Al-4V (ELI grade) and its Directionality}

Table3 shows the tensile test results obtained for Ti-6Al-4V (ELI grade) alloy.

The Ti-6Al-4V (ELI grade) alloy exhibits the significant anisotropy in tensile properties. From the fig.9 and fig 10, it is observed that the Ultimate tensile stress (UTS) and $0.2 \%$ yield stress values are more in circumferential directions than radial directions.

\begin{tabular}{|c|c|c|c|c|}
\hline SAMPLE & $\mathbf{0 . 2 \%}$ Y.S (MPa) & UTS(MPa) & $\mathbf{e}_{\mathbf{u}}$ & \% EL \\
\hline C-1 & 838 & 876 & 0.088 & 16 \\
\hline C-2 & 776 & 870 & 0.083 & 15 \\
\hline R-1 & 762 & 847 & 0.089 & 12 \\
\hline R-2 & 816 & 858 & 0.085 & 13 \\
\hline \multicolumn{5}{|r}{ Table3: TENSILE PROPERTIES OF Ti-6Al-4V(ELI Grade) } \\
\hline
\end{tabular}

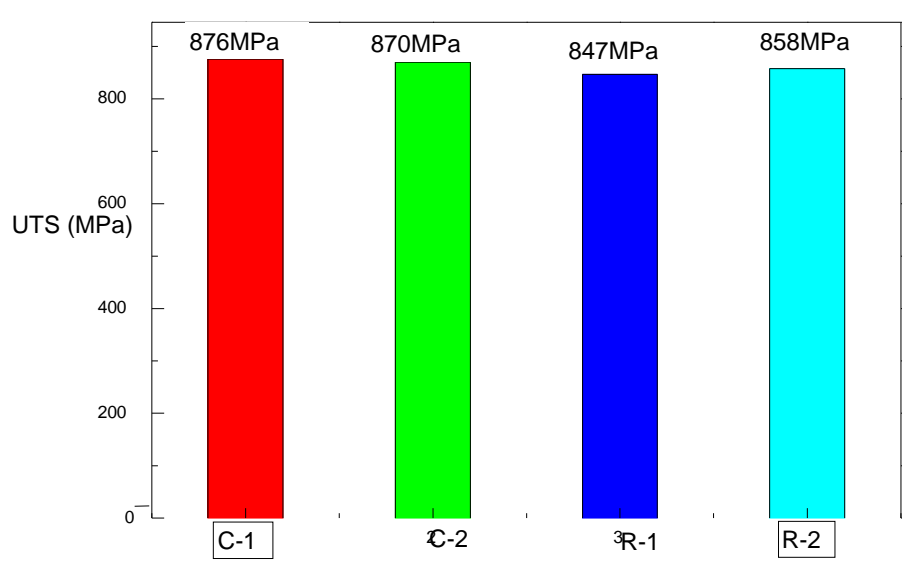

Figure.9: Sample - Ti-6Al-4V (ELI grade) 


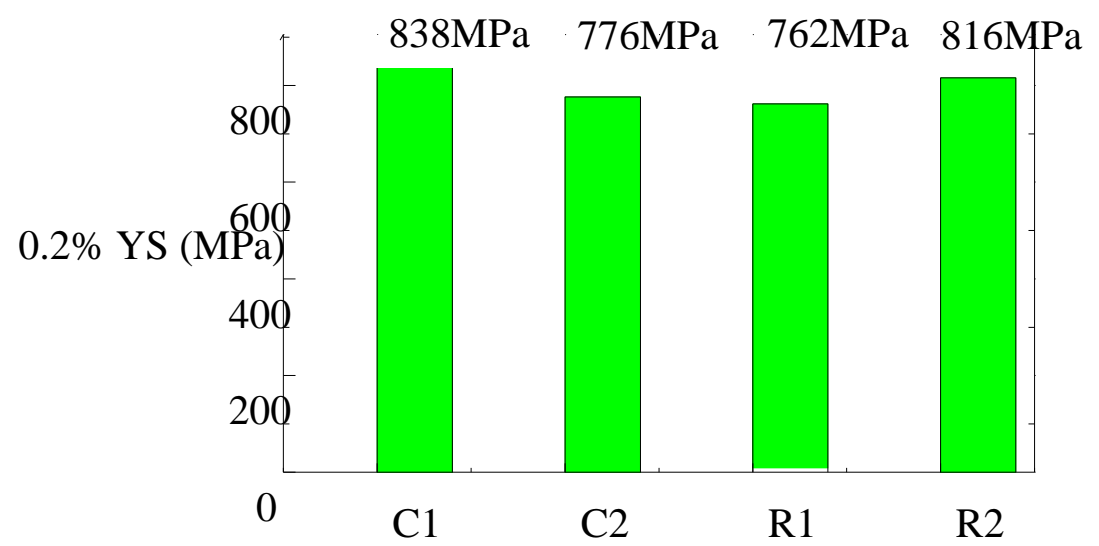

Figure. 10: Sample Ti-6Al-4V (ELI grade)

\subsection{Tensile deformation Behavior of Ti-6Al-4V (Ti-31)}

Table4 shows the tensile test results obtained for Ti-6Al-4V alloy.

\begin{tabular}{|c|c|c|c|}
\hline SAMPLE & $\mathbf{0 . 2 \%}$ Y.S (MPa) & UTS(MPa) & \% EL \\
\hline C-7 & 842 & 930 & 15.5 \\
\hline C-8 & 824 & 914 & 15.1 \\
\hline R-5 & 857 & 941 & 14.9 \\
\hline R-6 & 823 & 915 & 14.5 \\
\hline \multicolumn{2}{r|}{ Table 4 : TENSILE PROPERTIES OF Ti-6Al-4V (Ti-31) } \\
\hline
\end{tabular}


Tensile Deformation Characteristics of Ti-6Al-4V (ELI Grade) and effect of Interstitial Content

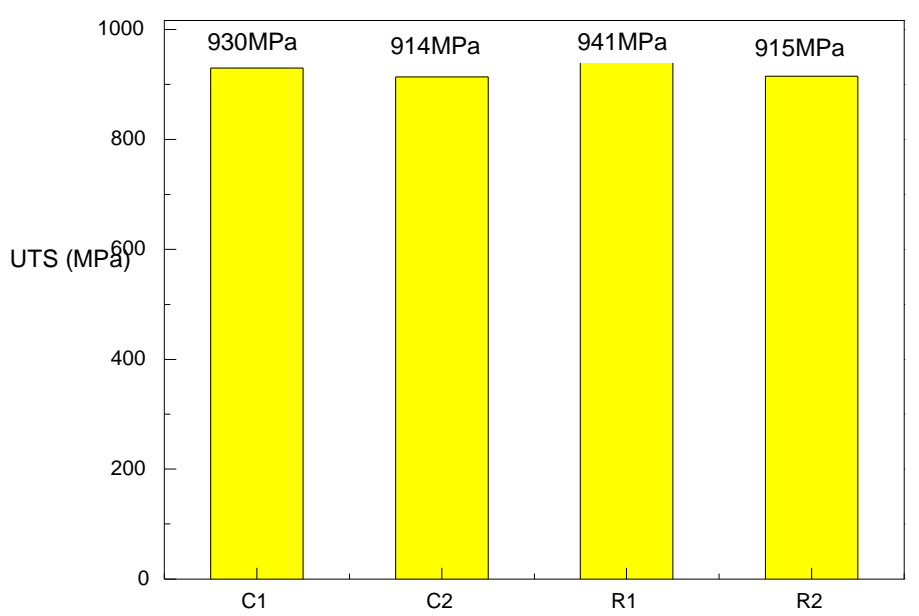

Figure. 15: SAMPLE Ti-6Al-4V (Ti-31)

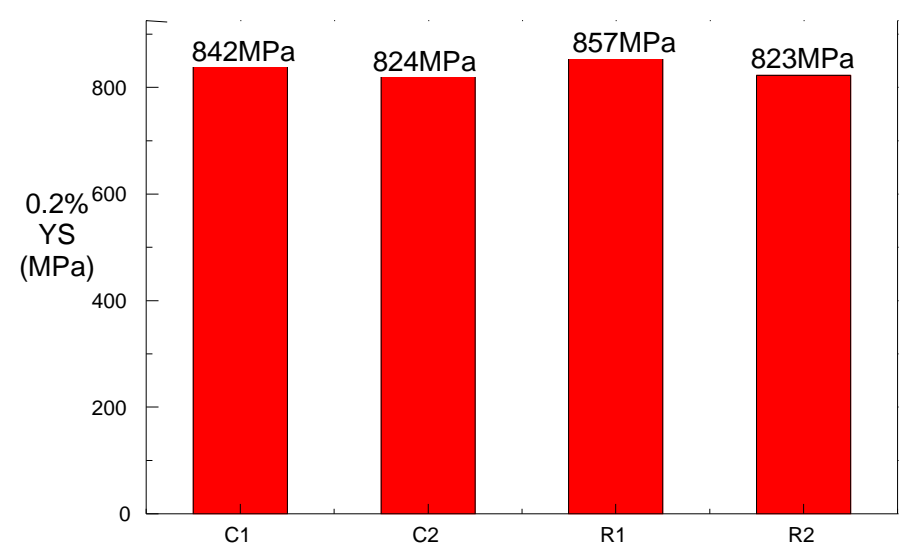

Figure 16 SAMPLES - Ti-6Al-4V (Ti-31)

\subsection{Comparison of Tensile Deformation of Ti-6Al-4V (ELI grade) with Ti- 6Al-4V (Ti-31)}

Figure.19 shows the comparison of ultimate tensile stress values of Ti-6Al-4V (ELI grade) with Ti-6Al-4V in both circumferential and radial directions. Fig.20 shows the comparison of $0.2 \%$ Yield stress of Ti-6Al-4V (ELI grade) with Ti-6Al-4V both circumferential and radial directions.Fig. 21 shows the comparison of $\%$ elongation of Ti-6Al-4V (ELI grade) with Ti-6Al-4V both circumferential and radial directions. The ultimate tensile stress (UTS) and $0.2 \%$ yield stress in both the directions for Ti6Al-4V (ELI grade) is less than the Ti-6Al-4V. Due to extra low interstitials grain size increases which leads to decrease in strength. 
N.Ranganayakulu, A.V.S.S.K.S. Gupta and N. Eswara Prasad

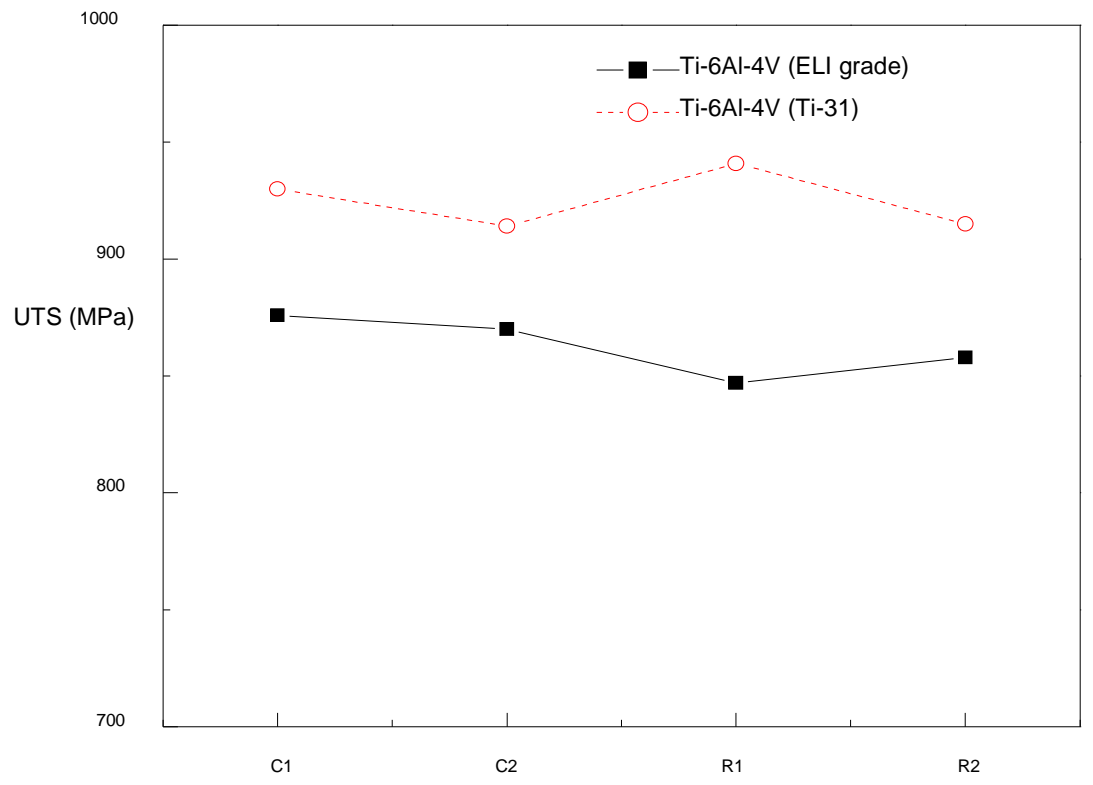

Figure19: Comparison UTS between Ti-6Al-4V(ELI grade) Vs. Ti-31

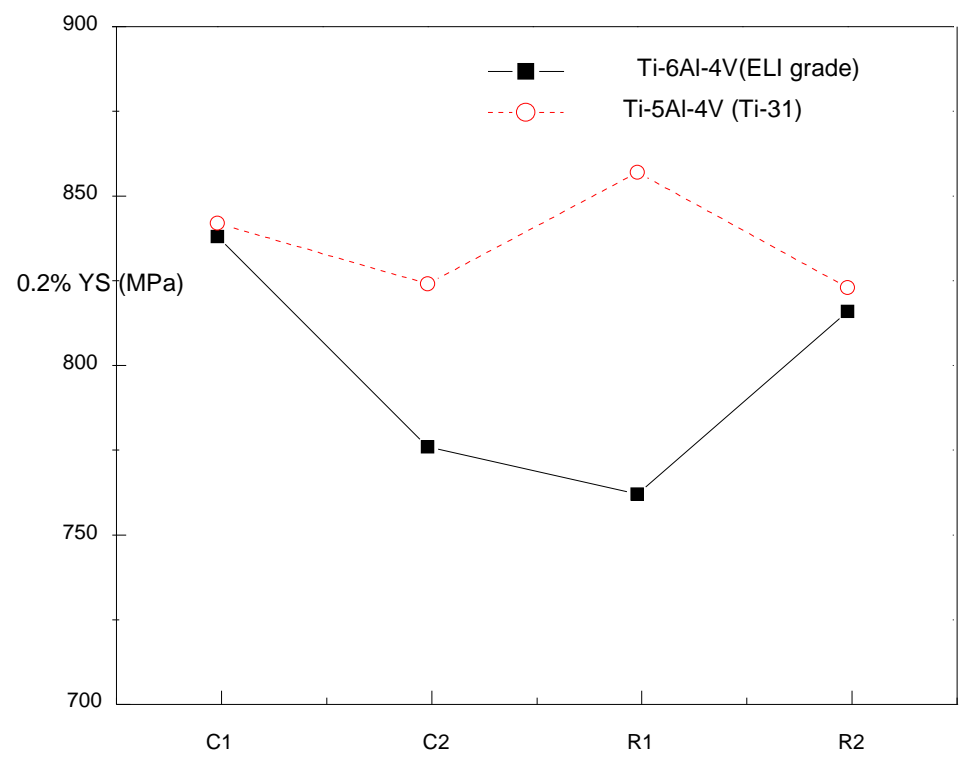

Figure. 20: Comparison 0.2\% YS between Ti-6Al-4V(ELI grade) Vs. Ti-31 
Tensile Deformation Characteristics of Ti-6Al-4V (ELI Grade) and effect of Interstitial Content

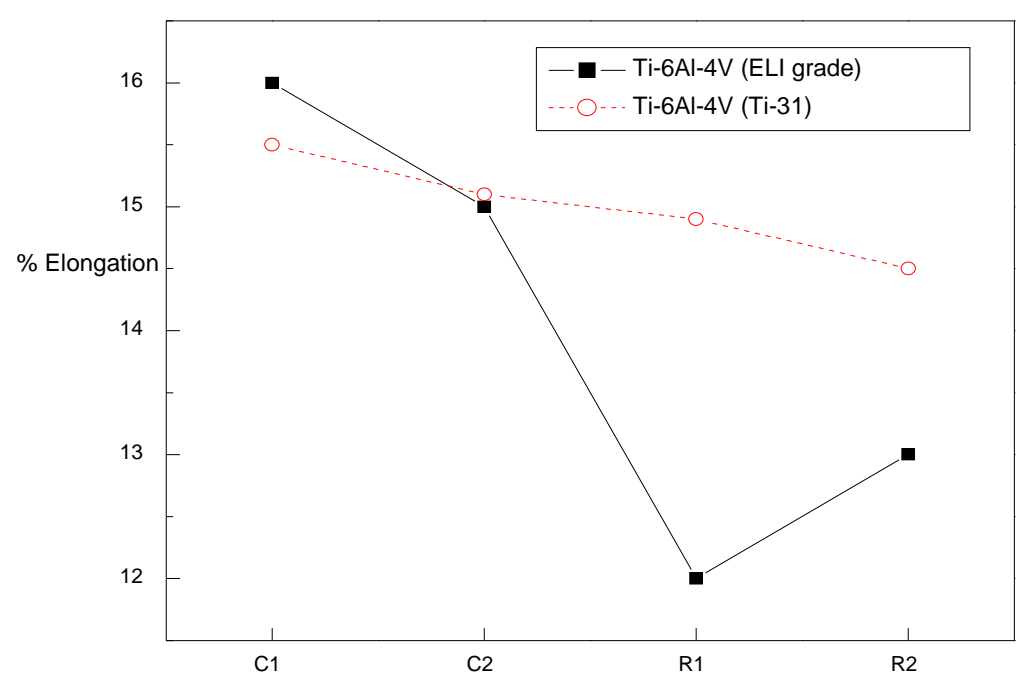

Figure.21\% Elongation between Ti-6Al-4V (ELI grade) Vs. Ti-31

\section{CONCLUSIONS}

- Ti-6Al-4V (ELI grade ) having the more strength in circumferential direction than the radial direction

- The strength of Ti-6Al-4V (ELI grade) contains less strength than the Ti-6Al$4 \mathrm{~V}$.

- It reveals that Extra low interstitials causes the decrease in strength of alloy.

\section{REFERENCES}

[1] SR Sealge and SJ Bartlo, 'Physical Metallurgy and Metallography of Titanium alloys', In Ref 1, PP 23-32.

[2] SR Sealge and SJ Bartlo, 'Metals Engineering', Vol.8, Aug 1968, PP. 110 .

[3] S. J. Auston and L.H.Chembers: in 'The Science, technology and applications of titanium', (ed R.I.Jaffee and N.E.Promisel), pp880-890, 1970 NY, Pergamon Press.

[4] J.E.Coyne: in 'The Science, technology and applications of teitenium', pp880-890, 1970 NY, Pergamon Press.

[5] Santos, E.C. "Mechanical properties of pure Titanium models processed by Selective Laser Melting". Proceedings of the Solid Freeform Fabrication Symposium. 2002, 180-186. 
[6] Semiatin, S., Seetharaman, V. and Weiss, I. "The thermomechanical processing of $\alpha / \beta$ Titanium Alloys". The Journal of The Minerals, Metals and Materials Society (TMS), 1997, 49.6: 33-39.

[7] Van Hooreweder, B., Moens, D., Boonen, R., Kruth, J. and Sas, P. "Analysis of fracture toughness and crack propagation of Ti-6Al-4V produced by Selective Laser Melting". Advanced Engineering Materials, 2012, 14.1-2: 92-97.

[8] Welsch, G., Boyer, R.. and Collings, E.W. "Materials Properties Handbook: Titanium Alloys ”.ASM international, 1994.

[9] Thijs, L., Verhaeghe, F., Craeghs, T., Humbeeck, J.V. and Kruth, J.P. “A study of themicrostructural evolution during Selective Laser Melting of Ti-6Al-4V". Acta Materialia, 2010,5 8.9: 3303-3312.

[10] Pederson, R. "Microstructure and phase transformation of Ti-6Al-4V". Doctoral Thesis, KTH Royal Institute of Technology, 2002.

[11] Peters, M., Gysler, A. and Lütjering, G. "Influence of texture on fatigue properties of Ti-6Al-4V". Metallurgical Transactions A, 1984, 15.8: 15971605.

[12] Lütjering, G. "Influence of processing on microstructure and mechanical properties of $\alpha+\beta$ Titanium Alloys". Materials Science and Engineering: A, 1998, 243.1: 32-45.

[13] Chesnutt, J., Thompson, A. and Williams, J.C. "Influence of Metallurgical Factors on the Fatigue Crack Growth Rate in $\alpha$-B Titanium Alloys". Rockwell International Thousand Oaks Calif Science Center, 1978.

[14] Chesnutt, J., Rhodes, C. and Williams, J.C. "Relationship between Mechanical Properties, Microstructure, and Fracture Topography in $\alpha+\beta$ Titanium Alloys". Special Technical Publication, 1976, 600: 99-138.

[15] Bhattacharyya, D. "The development of textures and microstructures in $\alpha+\beta$ Titanium Alloys", Doctoral Thesis, The Ohio State Univerisity, 2004.

[16] Iman, M.A., Gilmore, C.M., 1983. Fatigue and microstructural properties of quenched Ti.6Al.4V. Metall. Trans. A 14A, 233.240.

[17] Ding, R., Guo, Z.X., Wilson, A., 2002. Microstructure evolution of a Ti.6Al.4V alloy during thermo mechanical processing. Mater. Sci. Engng. A $327,233.245$. 
Tensile Deformation Characteristics of Ti-6Al-4V (ELI Grade) and effect of Interstitial Content

[18] Woei-Shyan Lee and Ming-Tong Lin (1997), "The Effect of Strain Rate and temperature on the Compressive Deformation Behavior of Ti-6Al-4V Alloy", journal of Materials Processing Technology, Vol. 71, pp. 235-246.

[19] H. Margolin and P. Cohen: in Titanium '80: Science and Technology H. Kimura and O. Izumi, eds., TMS, Warrendale, PA, 1980, pp 1555-61.

[20] Leyens C, Peters M. Titanium and titanium alloys - Fundamentals and applications. Weinheim: Wiley-VCH; 2003 